\title{
Cocoa powder enhances the level of antioxidative activity in rat plasma
}

\author{
Seigo Baba ${ }^{1}$, Naomi Osakabe ${ }^{1}$, Midori Natsume ${ }^{1}$, Akiko Yasuda ${ }^{1}$, Toshio Takizawa ${ }^{1}$, \\ Tetsuo Nakamura ${ }^{1}$ and Junji Terao ${ }^{2}$ \\ ${ }^{1}$ Functional Foods R\&D Laboratories, Meiji Seika Kaisha Ltd, 5-3-1, Chiyoda, Sakado-shi, Saitama 350-0289, Japan \\ ${ }^{2}$ Department of Nutrition, School of Medicine, The University of Tokushima, Tokushima, Japan
}

(Received 7 December 1999 - Revised 18 April 2000 - Accepted 10 May 2000)

\begin{abstract}
The aims of the present study were to determine the level of (-)-epicatechin (EC) and its metabolites in rat plasma after oral administration of cocoa powder and to evaluate the protective effect of cocoa powder in terms of suppressing the oxidation of plasma components. Rats were orally administered $1 \mathrm{~g}$ cocoa powder/kg body weight, containing $7.80 \mathrm{mg}$ EC, and their blood was collected before administration and at designated time intervals thereafter. The EC and its metabolites in plasma were treated with $\beta$-glucuronidase and/or sulfatase, then analysed by HPLC and by liquid chromatography-MS. Several EC-related compounds were detected in plasma such as free EC, and glucuronide, sulfate, and glucuronide-sulfate conjugates of non-methylated or methylated EC. All EC metabolites showed a maximum concentration in plasma at 30-60 min post-administration. Glucuronide conjugates of both nonmethylated and methylated EC were found in high concentration in plasma. Moreover, administration of cocoa powder significantly reduced the accumulation of lipid peroxides in plasma and significantly reduced the consumption of $\alpha$-tocopherol in plasma oxidized by treatment with 2,2'-azobis-(2-amidinopropane) dihydrochloride (AAPH (25 mmol/l)) or $\mathrm{CuSO}_{4}$ $(100 \mu \mathrm{mol} / \mathrm{l})$ compared with that in the case of plasma obtained before administration. The total EC concentration in plasma was negatively correlated with the level of accumulation of lipid peroxides in plasma oxidized by treatment with AAPH $(25 \mathrm{mmol} / \mathrm{l})$ and was positively correlated with the level of residual $\alpha$-tocopherol in plasma oxidized by treatment with $\mathrm{CuSO}_{4}(100 \mu \mathrm{mol} / \mathrm{l})$. These results indicate that EC in cocoa powder was absorbed from the digestive tract, that various conjugated forms of EC were generated in the digestive tract and distributed to the plasma, and that these enhanced the antioxidative activity of plasma.
\end{abstract}

Cocoa powder: Epicatechin: Absorption: Antioxidant

Several reports from epidemiological studies have indicated that the consumption of dietary flavonoids is inversely correlated with the occurrence of CHD and cancer (Hertog et al. 1993, 1995; Keli et al. 1996; Knekt et al. 1996). Flavonoids, which have several hydroxyl groups, are widely distributed in fruits and vegetables, so we consume these compounds in our daily diet (Cook \& Samman, 1996). Catechins, which are a type of flavonoid, such as (-)-epicatechin (EC), (-)-epigallocatechin, (-)epicatechingallate, (-)-epigallocatechingallate, (+)-catechin, and (+)-gallocatechin, are known to be present in green and black tea and other plant foods. Both epidemiological and in vitro studies suggest that catechins have effects on human health, serving to protect against CHD and cancer due to their antioxidative activity ( $\mathrm{Yu} \& \mathrm{Hsieh}$,
1991; Oguni et al. 1992; Yoshino et al. 1994; Ishikawa et al. 1997; Jankun et al. 1997; Yamanaka et al. 1997).

Previous studies have indicated that when EC, one of the catechins is administered, it is absorbed from the intestinal tract and exists as conjugated and/or methylated forms in plasma (Piskula \& Terao, 1998; Silva et al. 1998; Okushio et al. 1999). The final products of metabolized EC were found to be excreted via urine and bile (Hollman et al. 1997). Conjugation and methylation of the phenolic moiety led to a decrease in its antioxidative activity, at the point of scavenging chain-initiating oxygen radicals or chelating transition metal ions (Nanjo et al. 1996; Rice-Evans et al. 1996). However, Silva et al. (1998) demonstrated that administration of EC enhanced the level of antioxidative activity in rat plasma.

\footnotetext{
Abbreviations: AAPH, 2,2'-azobis-(2-amidinopropane) dihydrochloride; EC, (-)-epicatechin.

* Corresponding author: Seigo Baba, fax + 8149284 7569, email seigo_baba@meiji.co.jp
} 
Cacao beans (Theobroma cacao) have been used worldwide as a major ingredient of cocoa and chocolate. Cacao beans are rich in polyphenols, such as EC, (+)-catechin, quercetin (including its glucoside), clovamide, deoxyclovamide and procyanidin (Thompson et al. 1972; Sanbongi et al. 1998; Hammerstone et al. 1999). EC is a major component of the polyphenols in cacao beans, and it is also a monomer of procyanidin. According to previous reports, a crude polyphenol fraction extracted from cacao beans had marked antioxidant activity (Osakabe et al. 1998a,b; Sanbongi et al. 1998). On the other hand, Richelle et al. (1999) reported that EC in chocolate was rapidly absorbed and soon detected in human plasma, but they did not assess its metabolites. The effect of administration of cacao products on the level of antioxidative activity in plasma remains unclear.

The purpose of the present study was to examine the absorption of EC in cocoa powder and the appearance in rat plasma. Furthermore, we evaluated the protective effect of orally administered cocoa powder on the oxidation of plasma induced by a water-soluble radical generator or metal ions $\left(\mathrm{Cu}^{2+}\right)$.

\section{Materials and methods}

\section{Chemicals}

EC, D-saccharic acid 1,4-lactone, $\beta$-glucuronidase type VII-A, sulfatase type VIII and sulfatase type H-5 were purchased from Sigma Chemical Co. (St Louis, MO, USA). Other chemicals were commercially available products of analytical or HPLC grade.

Fermented and dried cacao beans were imported from Ecuador. Cocoa powder was obtained by roasting, cracking and compressing the beans at Meiji Seika Kaisha Ltd (Tokyo, Japan). The general composition of the cocoa powder was as follows (/100 g): $3.9 \mathrm{~g}$ moisture, $21.6 \mathrm{~g}$ protein, $14.7 \mathrm{~g}$ fat, $11.5 \mathrm{~g}$ carbohydrate, $27.1 \mathrm{~g}$ fibre, $7.7 \mathrm{~g}$ minerals, $8.59 \mathrm{~g}$ total polyphenol, $780 \mathrm{mg} \mathrm{EC}$, $305 \mathrm{mg}(+)$-catechin, $252 \mathrm{mg}$ procyanidin B2, $170 \mathrm{mg}$ procyanidin $\mathrm{C} 1,21.5 \mathrm{mg}$ 3-galactopyranosyl-ent-epicatechin- $(2 \alpha \rightarrow 7,4 \alpha \rightarrow 8)$-epicatechin, $275 \mathrm{mg}$ cinnamtannin A2. Total polyphenol content of cocoa powder was measured by the Prussian blue method (Price \& Butler, 1977). EC and CA in cocoa powder were determined by HPLC according to Osakabe et al. (1998a). Procyanidin B2, procyanidin C1, 3-galactopyranosyl-ent-epicatechin$(2 \alpha \rightarrow 7,4 \alpha \rightarrow 8)$-epicatechin and cinnamtannin A2 in cocoa powder were analysed using the modified method of Silva et al. (1991).

\section{Experimental animals}

Sprague-Dawley male rats were obtained at 8 weeks of age from Clea Japan Inc. (Tokyo, Japan). They were kept in a controlled environment at $23^{\circ} \mathrm{C}$ and $55 \%$ relative humidity under a $12 \mathrm{~h}$ dark-light cycle with free access to pelleted diet $\left(\mathrm{MF}^{\circledR}\right.$; Oriental Yeast Co. Ltd, Tokyo, Japan) and deionized water for 1 week. Cannulation of the femoral artery was performed under anaesthesia using diethyl ether.
A polyethylene tube was implanted into the femoral artery and sutured. After the operation, the rats were placed in restraining cages (KN; Natsume Seisakusho Co. Ltd, Tokyo, Japan) with free access to deionized water. Blood samples were collected from the cannulated femoral artery. Plasma was obtained by centrifugation at $1400 \mathrm{~g}$ for $10 \mathrm{~min}$ at $4^{\circ} \mathrm{C}$ and stored at $-80^{\circ} \mathrm{C}$ under $\mathrm{N}_{2}$ gas until required for analysis.

The present study was approved by the Animal Committee of Meiji Seika Functional Foods R\&D Laboratories, and the animals received humane care under the guidelines laid down by this committee.

\section{Determination of (-)-epicatechin and its metabolites in plasma by HPLC}

Post-operatively all rats ( $n$ 5) were deprived of food for $12 \mathrm{~h}$ before administration of the cocoa powder. Cocoa powder was suspended in deionized water $(1 \mathrm{~g} / 10 \mathrm{ml})$ and was administered orally ( $1 \mathrm{~g} / \mathrm{kg}$ body weight). Blood samples $(200 \mu \mathrm{l})$ were collected from the cannulated femoral artery into heparinized tubes before administration and at 15, 30, 60, 120, 180 and 300 min after administration. The levels of EC and its metabolites in rat plasma were determined by HPLC according to the method of Piskula \& Terao (1998). Glucuronide, sulfate or glucuronide-sulfate (sulfoglucuronide) conjugates of non-methylated or methylated EC were hydrolysed to non-conjugated EC by treatment with $\beta$-glucuronidase type VII-A, sulfatase type VIII, or sulfatase type H-5. The amount of each EC metabolite in the sample was calculated as the amount of EC after enzymic hydrolysis minus the amount of EC in non-methylated or methylated EC before hydrolysis (Piskula \& Terao, 1998).

\section{Determination of lipid peroxide in oxidation of plasma induced by 2,2'-azobis-(2-amidinopropane) dihydrochloride or copper sulphate solution}

Post-operatively all rats ( $n 5)$ were deprived of food for $12 \mathrm{~h}$ before administration of the cocoa powder. Cocoa powder was suspended in deionized water $(1 \mathrm{~g} / 10 \mathrm{ml})$ and was administered orally ( $1 \mathrm{~g} / \mathrm{kg}$ body weight). Blood samples $(300 \mu \mathrm{l})$ were collected from the cannulated femoral artery into heparinized tubes before administration and at 15, 30, 60, 120, 180 and 300 min after administration. 2,2'-Azobis(2-amidinopropane) dihydrochloride (AAPH; $50 \mathrm{mmol} / \mathrm{l}$; $100 \mu \mathrm{l})$ in saline $(9 \mathrm{~g} \mathrm{NaCl} / \mathrm{l})$ or $\mathrm{CuSO}_{4}(200 \mu \mathrm{mol} / \mathrm{l}$; $100 \mu \mathrm{l})$ in saline was added to $100 \mu \mathrm{l}$ plasma and the mixture was incubated at $37^{\circ} \mathrm{C}$. After incubation for designated time intervals, $30 \mu \mathrm{l}$ of the incubation mixture was transferred to another test-tube. The oxidative reaction was terminated either by refrigeration at $4^{\circ} \mathrm{C}$ (in the case of AAPH oxidation) or by adding $\mathrm{Na}_{2}$ EDTA (200 mmol/l; $5 \mu \mathrm{l}$ ), (in the case of $\mathrm{CuSO}_{4}$ oxidation). The lipid peroxide content of the oxidized sample was measured spectrophotometrically using a commercially available kit (Determiner LPO $^{\circledR}$; Kyowa Medics Co, Tokyo, Japan). 


\section{Measurement of $\alpha$-tocopherol in oxidation of plasma induced by 2,2'-azobis-(2-amidinopropane) dihydrochloride or copper sulphate solution}

Post-operatively all rats ( $n$ 5) were deprived of food for $12 \mathrm{~h}$ before administration of the cocoa powder. Cocoa powder was suspended in deionized water $(1 \mathrm{~g} / 10 \mathrm{ml})$ and was administered orally ( $1 \mathrm{~g} / \mathrm{kg}$ body weight). Blood samples $(300 \mu \mathrm{l})$ were collected from the cannulated femoral artery into heparinized tubes before administration and at 15, 30, 60, 120, 180 and 300 min after administration. $\alpha$-Tocopherol levels were determined by HPLC using electrochemical detection. After incubation and termination of the reaction under the conditions described earlier, $30 \mu \mathrm{l}$ of the incubation mixture was added to $270 \mu \mathrm{l}$ ethanol and mixed for $1 \mathrm{~min}$, then centrifuged at $3000 \mathrm{~g}$ for $5 \mathrm{~min}$ at $4^{\circ} \mathrm{C}$. The supernatant fraction was filtered through a $0.45 \mu \mathrm{m}$ nylon membrane and $20 \mu \mathrm{l}$ injected onto an HPLC column (TSKgel ODS-80Ts, $5 \mu \mathrm{m}, 150 \times 4.6 \mathrm{~mm}$; TOSOH, Tokyo, Japan) eluted with $20 \mathrm{mM}^{-\mathrm{LiClO}_{4}}$ in methanol-water $(97 \cdot 5: 2 \cdot 5, \mathrm{v} / \mathrm{v})$ as the mobile phase at a flow rate of $2.0 \mathrm{ml} / \mathrm{min}$. The elute was monitored using an amperometric electrochemical detector (EC-8020; $\mathrm{TOSOH})$ with the working potential set at $+600 \mathrm{mV}$.

\section{Liquid chromatography-MS analysis of EC and its metabolites in plasma}

Post-operatively all rats ( $n$ 4) were deprived of food for $12 \mathrm{~h}$ before administration of the cocoa powder. Cocoa powder was suspended in deionized water $(1 \mathrm{~g} / 10 \mathrm{ml})$ and was administered orally ( $1 \mathrm{~g} / \mathrm{kg}$ body weight). At $60 \mathrm{~min}$ post-administration, for the purpose of identification of EC and its metabolites in plasma, blood samples $(500 \mu \mathrm{l})$ were collected from the cannulated femoral artery into heparinized tubes under diethyl ether anaesthesia. Plasma was obtained by centrifugation at $1400 \mathrm{~g}$ for $10 \mathrm{~min}$ at $4^{\circ} \mathrm{C}$. Plasma samples were hydrolysed with sulfatase type $\mathrm{H}-5$ and extracted as described earlier (Piskula \& Terao, 1998). HPLC-MS analyses of plasma extracts were performed using an HP 1100 Series HPLC (Hewlett Packard, Palo Alto, CA, USA) equipped with an auto-injector, a binary HPLC pump, and a column heater, interfaced with an HP Series 1100 mass selective detector with an API-ES ionization chamber (Hewlett Packard, Avondale, PA, USA). The plasma extract was injected onto an HPLC column (CAPCELL PACK-UG120, $150 \times 2.0 \mathrm{~mm}$ i.d.; Shiseido, Tokyo, Japan) eluted with a mixture of $0.03 \%$ $(\mathrm{v} / \mathrm{v})$ formic acid in water (A) and acetonitrile (B) as the mobile phase. Separations were done using 10-50\% linear gradients of B in A (0-30 min). The flow rate was $0.2 \mathrm{ml} /$ min. The conditions for analysis in the negative-ion mode were as follows: capillary voltage $4500 \mathrm{~V}$, fragmentor $90 \mathrm{~V}$, nebulizing pressure $276 \mathrm{kPa}$; drying gas temperature $320^{\circ} \mathrm{C}$; drying gas flow $8 \mathrm{l} / \mathrm{min}$. Data were analysed on an HP Chem Station (Hewlett Packard, Avondale, PA, USA) using selective ion monitoring.

\section{Calculations and statistical analysis}

Data are presented as means with their standard errors.
Data were analysed by Student's paired $t$ test, comparing values before and after administration of cocoa powder. Differences were considered significant at $P<0 \cdot 05$. All statistical analyses were performed using SPSS for Windows version 7.5.1 software (SPSS Japan Inc., Tokyo, Japan).

\section{Results}

\section{Plasma concentrations of (-)-epicatechin and its metabolites in rats}

Typical HPLC chromatograms of rat plasma before and at 60 min after cocoa powder administration are shown in Fig. 1. Two peaks, eluted at $12 \mathrm{~min}$ and $26 \mathrm{~min}$, were observed after enzymic treatment (Fig. 1(c)). The first peak (eluted at $12 \mathrm{~min}$ ) showed the same chromatographic profile as the EC standard. Typical liquid chromatography-MS chromatograms for rat plasma obtained $60 \mathrm{~min}$ after administration, treated with sulfatase type H-5, are shown in Fig. 2. According to the liquid chromatography-MS results, a molecular ion $[\mathrm{M}-\mathrm{H}]^{-}$peak obtained at $\mathrm{m} / \mathrm{z} 289$ (the peak eluted at 12 min in the HPLC analysis) was identified as EC (Fig. 2(a)). The second peak (eluted at 26 min) was determined to be methylated EC according to the method of Piskula \& Terao (1998). The $[\mathrm{M}-\mathrm{H}]^{-}$peak obtained at $\mathrm{m} / \mathrm{z}$ 303 (the peak eluted at $26 \mathrm{~min}$ in the HPLC analysis) was

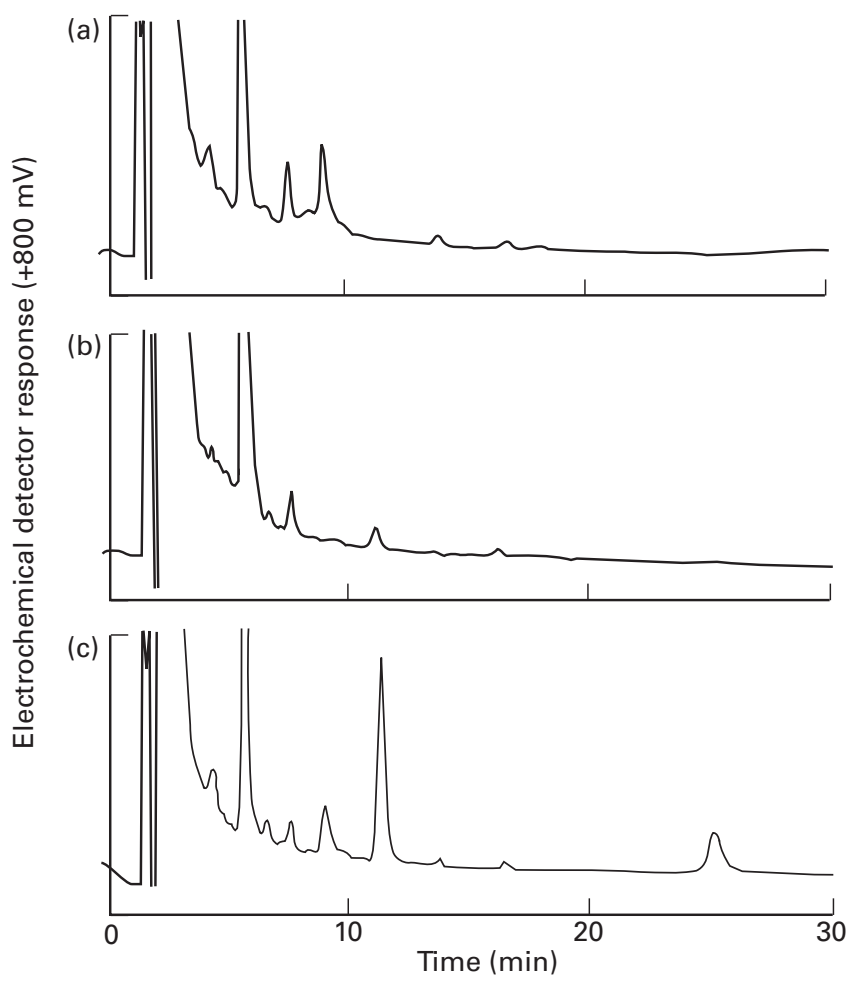

Fig. 1. Typical HPLC chromatograms of samples of rat plasma obtained before (a) and at $60 \mathrm{~min}$ after oral administration of cocoa powder ( $1 \mathrm{~g} / \mathrm{kg}$ body weight), without (b) or with (c) enzymic treatment using sulfatase (type $\mathrm{H}-5$ ). Peaks at 12 and 26 min were identified as non-methylated (-)-epicatechin and methylated (-)epicatechin respectively. For details of experimental procedures, see p. 674 

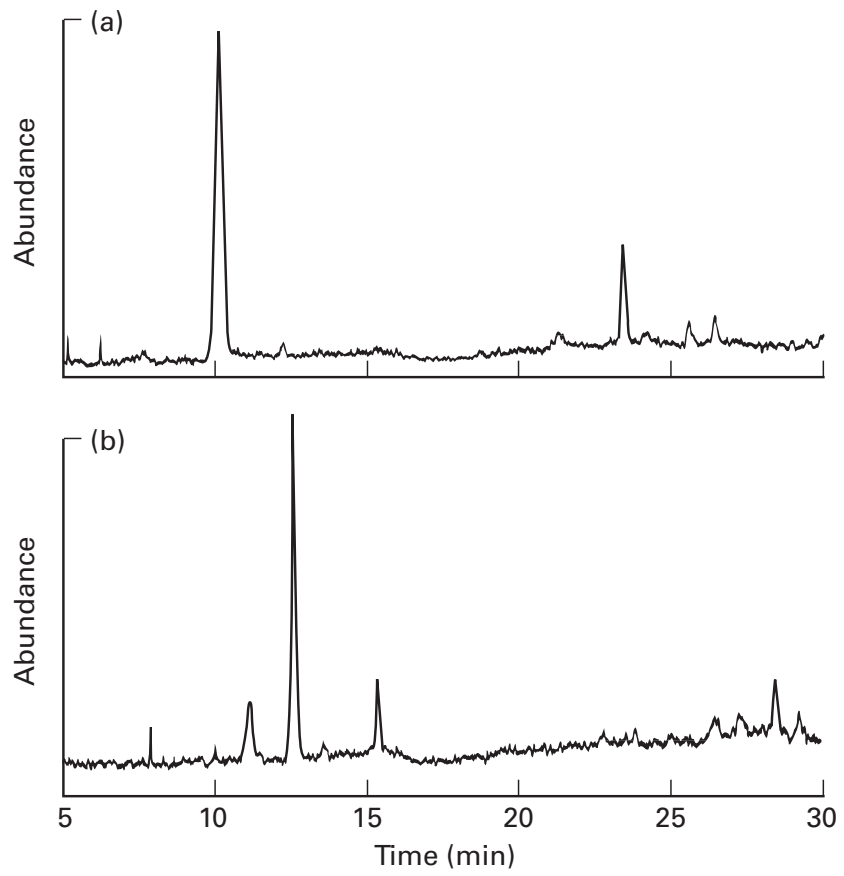

Fig. 2. Typical liquid chromatography-MS chromatograms for rat plasma obtained at $60 \mathrm{~min}$ after oral administration of cocoa powder $(1 \mathrm{~g} / \mathrm{kg}$ body weight), with enzymic treatment using sulfatase (type $\mathrm{H}-5)$. The molecular ion $[\mathrm{M}-\mathrm{H}]^{-}$peaks obtained at $\mathrm{m} / \mathrm{z} 289(\mathrm{a})$ and at $\mathrm{m} / \mathrm{z} 303$ (b) were identified as (-)-epicatechin and O-methyl-(-)epicatechin respectively. For details of experimental procedures, see p. 674.

identified as methylated EC based on molecular weight (Fig. 2(b)).

The plasma concentrations of EC and its metabolites after the administration of cocoa powder are shown in Fig. 3. By enzymic treatment of plasma the level of EC and its metabolites such as glucuronide, sulfate and sulfoglucuronide conjugates were determined as being non-methylated (Fig. 3(a)) or methylated forms (Fig. 3(b)). However, the methylated form of non-conjugated EC was not detected after administration of cocoa powder. All EC metabolites reached a maximum concentration in plasma at 30-60 min post-administration. The level of total metabolites at 30 and 60 min post-administration was 12.5 (SE 1.61) and 12.5 (SE 1.84) $\mu \mathrm{mol} / \mathrm{l}$ respectively. The major components were glucuronide conjugates of non-methylated and methylated forms. At $30 \mathrm{~min}$ post-administration, the level of the nonmethylated form was 6.69 (SE 0.52) $\mu \mathrm{mol} / \mathrm{l}$ (Fig. 3(a)) and that of the methylated form was 1.71 (SE 0.27) $\mu \mathrm{mol} / \mathrm{l}$ (Fig. 3(b)). Moreover, at $60 \mathrm{~min}$ post-administration, the level of the non-methylated form was 6.92 (SE 0.43) $\mu \mathrm{mol} / \mathrm{l}$ (Fig. 3(a)) and that of the methylated form was 2.04 (SE 0.24) $\mu \mathrm{mol} / \mathrm{l}$ (Fig. 3(b)). The glucuronide-conjugated forms at $30 \mathrm{~min}$ and 60 min post-administration comprised 67.2 and $71.7 \%$ of the total metabolites respectively. The total level of non-methylated EC in plasma at $300 \mathrm{~min}$ post-administration was $50.4 \%$ lower than that at 30 min postadministration (Fig. 3(a)). On the other hand, the total level of methylated EC in plasma at 300 min post-administration was $96.3 \%$ lower than that at 30 min post-administration (Fig. 3(b)). Thus, total non-methylated:methylated EC in
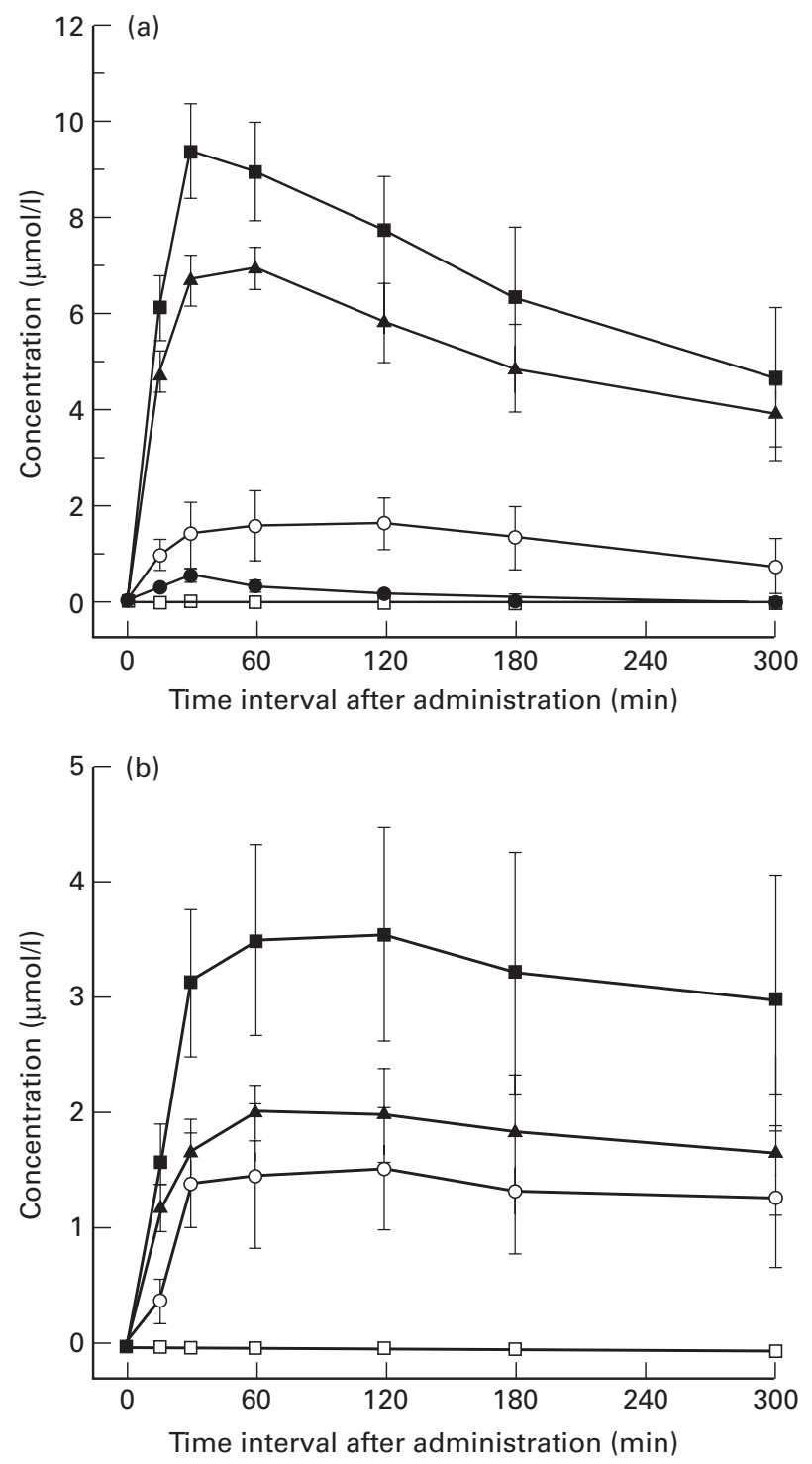

Fig. 3. Profiles of (-)-epicatechin (EC) and its metabolites in rat plasma after oral administration of cocoa powder $(1 \mathrm{~g} / \mathrm{kg}$ body weight). Non-conjugated (-๑), conjugated with sulfoglucuronide

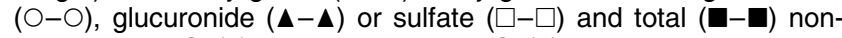
methylated EC (a) and methylated EC (b). Blood samples were collected from the femoral artery before and $6 \mathrm{~h}$ after administration of cocoa powder. Values are means with their standard errors represented by vertical bars for five rats. For details of experimental procedures, see p. 674

plasma was 2.96 at 30 min post-administration and 1.55 at $300 \mathrm{~min}$ post-administration.

Lipid peroxide accumulation and $\alpha$-tocopherol consumption in plasma induced by treatment with a radical generator or metal ions (copper ions)

Table 1 shows the profile of accumulation of lipid peroxides in plasma obtained before $(0 \mathrm{~min})$ and after $(15,30,60,120,180$ and $300 \mathrm{~min})$ administration of cocoa powder, oxidized by treatment with AAPH $(25 \mathrm{mmol} / \mathrm{l}$; incubation period $0,60,120$ and $180 \mathrm{~min}$ ) or $\mathrm{CuSO}_{4}$ 
Table 1. Lipid peroxide accumulation ( $\mu \mathrm{mol} / \mathrm{l})$ in plasma obtained from rats before and after oral administration of cocoa powder $(1 \mathrm{~g} / \mathrm{kg}$ body weight), induced by treatment with water-soluble radical generator 2,2'-azobis-(2-amidinopropane) dihydrochloride (AAPH; $25 \mathrm{mmol} / \mathrm{l})$ or copper ions (copper sulphate; $100 \mu \mathrm{mol} / \mathrm{l}) \dagger$

(Values are means with their standard errors for five rats)

\begin{tabular}{|c|c|c|c|c|c|c|c|c|c|}
\hline \multirow{2}{*}{\multicolumn{2}{|c|}{ Period after administration (min)... }} & & \multicolumn{7}{|c|}{ Lipid peroxide accumulation $(\mu \mathrm{mol} / \mathrm{l})$} \\
\hline & & & 0 (Before) & 15 & 30 & 60 & 120 & 180 & 300 \\
\hline \multicolumn{10}{|l|}{ AAPH } \\
\hline \multirow[t]{7}{*}{ Incubation period $(\mathrm{min})$ : } & 0 & $\begin{array}{l}\text { Mean } \\
\text { SE }\end{array}$ & ND & $\begin{array}{l}0.66 \\
0.50\end{array}$ & ND & ND & ND & ND & ND \\
\hline & 60 & Mean & $41 \cdot 7$ & $47 \cdot 5$ & 34.5 & $35 \cdot 8$ & $39 \cdot 8$ & $37 \cdot 3$ & $43 \cdot 7$ \\
\hline & & SE & $2 \cdot 0$ & $5 \cdot 8$ & $6 \cdot 1$ & 3.4 & $4 \cdot 2$ & $3 \cdot 0$ & 1.9 \\
\hline & 120 & Mean & 121 & 128 & 102 & $103^{*}$ & 108 & $103^{*}$ & 114 \\
\hline & & SE & 6 & 12 & 7 & 8 & 2 & 3 & 3 \\
\hline & 180 & Mean & 193 & 185 & 157 & $156^{*}$ & 177 & 162 & 177 \\
\hline & & SE & 11 & 13 & 12 & 10 & 6 & 3 & 5 \\
\hline \multicolumn{10}{|l|}{$\mathrm{CuSO}_{4}$} \\
\hline \multirow[t]{8}{*}{ Incubation period $(\mathrm{min})$ : } & 0 & Mean & 1.59 & 0.18 & 0.53 & 0.53 & 0.35 & 0.53 & 1.42 \\
\hline & & SE & 0.71 & 0.13 & 0.35 & 0.35 & 0.24 & 0.35 & 0.91 \\
\hline & 120 & Mean & $51 \cdot 2$ & $43 \cdot 6$ & 35.4 & $31 \cdot 7$ & $40 \cdot 7$ & $37 \cdot 2$ & $36 \cdot 6^{\star}$ \\
\hline & & SE & $8 \cdot 2$ & $9 \cdot 1$ & $7 \cdot 4$ & 4.9 & $6 \cdot 7$ & 5.4 & $3 \cdot 3$ \\
\hline & 240 & Mean & 104 & $89 \cdot 7$ & 100 & $69 \cdot 2$ & $90 \cdot 3$ & 79.5 & $63 \cdot 2$ \\
\hline & & SE & 13 & $11 \cdot 3$ & $19 \cdot 2$ & $7 \cdot 7$ & $13 \cdot 3$ & 9.4 & 4.0 \\
\hline & 360 & Mean & 133 & 114 & 137 & $96 \cdot 7$ & 122 & 106 & $78 \cdot 6^{\star}$ \\
\hline & & SE & 17 & 9 & 21 & $12 \cdot 6$ & 16 & 12 & $3 \cdot 6$ \\
\hline
\end{tabular}

ND, not detectable.

Mean values were significantly different from that before administration: ${ }^{*} P<0.05$.

† For details of experimental procedures, see p. 674.

(100 $\mu \mathrm{mol} / \mathrm{l}$; incubation period 0, 120, 240 and $360 \mathrm{~min}$ ). In the case of oxidation by AAPH, the administration of cocoa powder significantly reduced $(P<0.05)$ the accumulation of lipid peroxides in plasma obtained at 60 and 180 min post-administration. Furthermore, in the case of oxidation by $\mathrm{CuSO}_{4}$, the accumulation of lipid peroxides in plasma obtained before administration was significantly higher $(P<0.05)$ than that in the plasma obtained at 300 min post-administration.
Table 2 shows the profile of consumption of $\alpha$ tocopherol in plasma obtained before $(0 \mathrm{~min})$ and after $(15,30,60,120,180$ and $300 \mathrm{~min})$ administration of cocoa powder, oxidized by treatment with AAPH $(25 \mathrm{mmol} / \mathrm{l}$; incubation period $0,30,60,90$ and $120 \mathrm{~min}$ ) or $\mathrm{CuSO}_{4}$ (100 $\mu \mathrm{mol} / \mathrm{l}$; incubation period $0,30,60,120$ and $180 \mathrm{~min})$. In the case of oxidation by AAPH, the level of $\alpha$-tocopherol in the plasma obtained before administration was significantly lower than that in the plasma obtained at

Table 2. $\alpha$-Tocopherol consumption $(\%)^{\dagger}$ in plasma obtained from rats before and after oral administration of cocoa powder (1 $\mathrm{g} / \mathrm{kg}$ body weight), induced by treatment with water-soluble radical generator 2,2'-azobis-(2-amidinopropane) dihydrochloride (AAPH; $25 \mathrm{mmol} / \mathrm{l})$ or copper ions (copper sulphate; $100 \mu \mathrm{mol} / \mathrm{l}) \ddagger$

(Values are means with their standard errors for five rats)

\begin{tabular}{|c|c|c|c|c|c|c|c|c|c|}
\hline \multirow{2}{*}{\multicolumn{2}{|c|}{ Period after administration $(\min ) \ldots$}} & & \multicolumn{7}{|c|}{$\alpha$-Tocopherol consumption (\%) } \\
\hline & & & 0 (Before) & 15 & 30 & 60 & 120 & 180 & 300 \\
\hline \multicolumn{10}{|l|}{ AAPH } \\
\hline \multirow[t]{8}{*}{ Incubation period $(\mathrm{min})$ : } & 30 & Mean & 88.7 & $92 \cdot 0$ & $89 \cdot 3$ & $90 \cdot 6$ & $95 \cdot 1$ & $82 \cdot 7$ & $75 \cdot 6$ \\
\hline & & SE & 7.45 & 0.9 & 3.9 & $3 \cdot 3$ & $3 \cdot 1$ & $5 \cdot 0$ & $7 \cdot 5$ \\
\hline & 60 & Mean & 69.9 & $80 \cdot 3$ & $81 \cdot 5^{\star}$ & $75 \cdot 9$ & $68 \cdot 8$ & $67 \cdot 1$ & $62 \cdot 1$ \\
\hline & & SE & $5 \cdot 9$ & $2 \cdot 9$ & $3 \cdot 1$ & $1 \cdot 8$ & $2 \cdot 5$ & $4 \cdot 2$ & $6 \cdot 0$ \\
\hline & 90 & Mean & $16 \cdot 0$ & $50 \cdot 2^{\star \star \star}$ & $55 \cdot 8^{\star *}$ & 28.9 & $28 \cdot 2$ & $31 \cdot 1$ & $12 \cdot 1$ \\
\hline & & SE & $3 \cdot 1$ & $4 \cdot 7$ & $6 \cdot 1$ & $7 \cdot 8$ & 8.0 & $5 \cdot 0$ & 4.6 \\
\hline & 120 & Mean & $2 \cdot 02$ & $5 \cdot 89$ & $15 \cdot 7$ & $3 \cdot 78$ & $2 \cdot 46$ & $2 \cdot 74^{*}$ & $0 \cdot 86^{*}$ \\
\hline & & SE & 0.45 & 1.88 & $6 \cdot 7$ & 0.99 & 0.36 & 0.52 & $0 \cdot 13$ \\
\hline \multicolumn{10}{|l|}{$\mathrm{CuSO}_{4}$} \\
\hline \multirow[t]{8}{*}{ Incubation period $(\mathrm{min})$ : } & 30 & Mean & 69.5 & 83.9 & $87 \cdot 0$ & $89 \cdot 0$ & $79 \cdot 0$ & $82 \cdot 0$ & $87 \cdot 3$ \\
\hline & & SE & $7 \cdot 6$ & $2 \cdot 0$ & $2 \cdot 3$ & $1 \cdot 2$ & 3.0 & $3 \cdot 8$ & $5 \cdot 0$ \\
\hline & 60 & Mean & 38.4 & $65 \cdot 0^{*}$ & $58 \cdot 6^{\star}$ & $60 \cdot 4^{\star}$ & $56 \cdot 0^{\star \star}$ & $63 \cdot 0^{*}$ & $68 \cdot 4^{\star *}$ \\
\hline & & SE & 3.9 & $3 \cdot 8$ & $3 \cdot 7$ & $4 \cdot 0$ & 2.5 & $6 \cdot 0$ & 4.3 \\
\hline & 120 & Mean & $10 \cdot 4$ & $23 \cdot 2$ & $18 \cdot 6$ & $15 \cdot 7$ & $16 \cdot 9$ & $20 \cdot 8^{*}$ & $18 \cdot 0^{*}$ \\
\hline & & SE & $2 \cdot 0$ & 5.4 & $5 \cdot 7$ & $0 \cdot 8$ & $3 \cdot 1$ & $1 \cdot 2$ & $1 \cdot 3$ \\
\hline & 180 & Mean & $2 \cdot 87$ & 7.92 & $5 \cdot 72$ & $5 \cdot 00^{*}$ & 6.53 & $5 \cdot 93^{*}$ & $5 \cdot 36^{\star}$ \\
\hline & & SE & 0.62 & $2 \cdot 18$ & 2.09 & 0.59 & 1.51 & 0.44 & 0.39 \\
\hline
\end{tabular}

Mean values were significantly different from that before administration: ${ }^{*} P<0.05,{ }^{\star \star} P<0.01,{ }^{* \star} P<0.001$

$\dagger$ Values relative to $\alpha$-tocopherol levels at 0 min incubation.

‡ For details of experimental procedures, see p. 674. 
$15(P<0.001), 30(P<0.05$ and $P<0.01), 180(P<$ $0.05)$ and $300(P<0.05)$ min post-administration (Table 2). Moreover, in the case of oxidation by $\mathrm{CuSO}_{4}$, the level of $\alpha$-tocopherol in the plasma obtained before administration was significantly lower than that in the plasma obtained at $15(P<0.05), 30(P<0.05), 60(P<0.05)$, $120(P<0.01), 180(P<0.05)$ and $300(P<0.01$ and $P<0.05)$ min post-administration (Table 2 ).

\section{Discussion}

Previous reports have indicated that crude polyphenol fractions extracted from Theobroma cacao and their components showed antioxidative activity in vitro, in experiments involving linoleic acid oxidation, erythrocyte membrane ghosts and a microsomal lipid peroxidation system (Osakabe et al. 1998a,b; Sanbongi et al. 1998). Moreover, in in vivo investigations using hypercholesterolaemic rabbits or $\alpha$-tocopherol-deficient rats as animal models, similarly crude polyphenol fractions from Theobroma cacao were found to have protective effects against oxidative stress induced by free radicals (N Osakabe, $\mathrm{M}$ Yamagishi, T Takizawa, T Osawa, M Natsume, T Adachi, R Hirano, H Itakura and K Kondo, unpublished results). These results suggest that Theobroma cacao has potent antioxidative activity; however, the bioavailability in terms of intestinal absorption and the metabolic conversion of polyphenols in Theobroma cacao remain unclear. Terao et al. (1994) demonstrated that EC, a major component of the polyphenol fraction of Theobroma cacao, was superior to $\alpha$-tocopherol in protection of phospholipid bilayers against oxygen radicals in an aqueous system. It is not clear, however, whether after oral administration of cocoa powder the polyphenols in Theobroma cacao show antioxidative activity in plasma. In the present study, we characterized the following variables. First, the profile of EC and its metabolites in rat plasma after oral administration of cocoa powder was determined. Second, the accumulation of lipid peroxides and the consumption of $\alpha$-tocopherol in plasma oxidized by treatment with AAPH as a water-soluble radical generator or by $\mathrm{CuSO}_{4}$ as a source of metal ions, under the conditions described earlier, was evaluated.

There have been many reports concerning the absorption of EC from the digestive tract (Zhang et al. 1997; Yang et al. 1998; Richelle et al. 1999), but the number of studies investigating the profile of EC and its metabolites is small. EC has been detected as a sulfate-conjugated form in human plasma after supplementation of the diet with decaffeinated green tea (Lee et al. 1995). It has also been reported that the most predominant metabolites of EC were $3^{\prime}$-O-methyl-(-)-epicatechin conjugates under conditions where EC was administered at a dose of $1720 \mu \mathrm{mol} / \mathrm{kg}$ body weight (Okushio et al. 1999). Silva et al. (1998) showed that glucuronide, sulfate and sulfoglucuronideconjugated forms of $O$-methylated or non-methylated EC were present in rat plasma after administration of EC at $172 \mu \mathrm{mol} / \mathrm{kg}$ body weight. In their study the major EC metabolite was the glucuronide-conjugated non-methylated form, and the non-conjugated form of EC accounted for only $7 \%$ of the total metabolites. Piskula \& Terao (1998) and Okushio et al. (1999) indicated that all EC metabolites in plasma reached maximum concentrations within $2 \mathrm{~h}$ after administration of EC at doses of $172 \mu \mathrm{mol}$ and $1720 \mu \mathrm{mol} / \mathrm{kg}$ body weight respectively. It has also been reported that, after intake of dark chocolate, all nonmethylated EC was absorbed, it was detected in human plasma after enzymic hydrolysis, and its concentrations reached a maximum in the period from 2 to $3 \mathrm{~h}$ after intake of the chocolate (Richelle et al. 1999). In the present study, as shown in Fig. 1, the EC metabolites detected after cocoa powder administration were mainly glucuronide- and sulfoglucuronide-conjugates of non-methylated or methylated EC. Total EC metabolite concentrations in plasma reached a maximum in the period from $30 \mathrm{~min}$ to $60 \mathrm{~min}$ post-administration. A previous study demonstrated that the highest levels of glucuronosyltransferase activity are found in the upper half of the small intestine, in the caecum and in the upper half of the large intestine (Piskula \& Terao, 1998). EC might be conjugated immediately with glucuronic acid by a glucuronosyltransferase while passing through the intestinal mucosa. According to our results, the main EC metabolite in blood after cocoa powder administration is the glucuronide-conjugated non-methylated form; this finding supports the hypothesis mentioned earlier. The type of EC metabolites in blood and their concentrations may differ depending on the quantity administered or the subject. For instance, in the present study the animals were administered a dose of $26.9 \mu \mathrm{mol} \mathrm{EC} / \mathrm{kg}$ body weight, and this dose was low compared with that used in previous experiments. However, these results suggest that EC in cocoa powder could be absorbed and metabolized in a manner similar to the EC from other sources.

Many in vitro studies have shown that catechins serve as an effective antioxidant in biological matter such as plasma. Lotito \& Fraga (1998) showed that addition of (+)-catechin to human plasma prevented the accumulation of 2-thiobarbituric acid-reactive substances and delayed the depletion of $\alpha$-tocopherol and $\beta$-carotene oxidized by AAPH or $2,2^{\prime}$-azobis (2,4-valeronitrile). It was expected that the administered catechins absorbed and distributed to plasma would show hardly any antioxidative activity compared with the level of activity observed on addition of catechins to plasma in vitro, because the absorbed catechins mainly existed as conjugated derivatives of nonmethylated or methylated EC. Bors et al. (1990) suggested that the catechol structure is essential to free radicalscavenging activity in the case of flavanol-type flavonoids. However, Silva et al. (1998) pointed out that EC administration enhanced the level of antioxidative activity in rat plasma, although most EC in the blood existed as conjugated or methylated forms, or both. Okushio et al. (1999) and Harada et al. (1999) reported that (-)epicatechin-5-O- $\beta$-glucuronide was present in rat plasma as an EC metabolite after EC administration. As this conjugated metabolite contains a catechol structure, this metabolite may serve as an effective antioxidant in plasma.

The present study has revealed that the accumulation of lipid peroxides and the consumption of $\alpha$-tocopherol in rat plasma oxidized by treatment with AAPH $(25 \mathrm{mmol} / \mathrm{l})$ or $\mathrm{CuSO}_{4}(100 \mu \mathrm{mol} / \mathrm{l})$ were significantly suppressed $(P<$ 0.05 ) by the administration of cocoa powder (Tables 1 and 2). A different tendency was evident in plasma oxidation 
when comparing AAPH $(25 \mathrm{mmol} / \mathrm{l})$ and $\mathrm{CuSO}_{4}$ $(100 \mu \mathrm{mol} / \mathrm{l})$ as the oxidizing agents. There have been some reports that flavonoids inhibit lipid peroxidation by scavenging oxygen radicals and/or by chelating metal ions (Ratty \& Das, 1988; Afanas'ev et al. 1989; van Acker et al. 1996). The cocoa powder used in the present study contained (+)-catechin and procyanidins in addition to EC. Thus, not only EC but also other polyphenols in the cocoa powder might have contributed to the protective effect against oxidative stress in the present study. However, further study will be needed to clarify the bioavailability of procyanidin oligomers present in cocoa powder.

The dose of EC administered in the present study (26.9 $\mu \mathrm{mol} / \mathrm{kg}$ body weight) was much lower than that in previous studies in rats. It has been reported that administration of EC at 172 or $862 \mu \mathrm{mol} / \mathrm{kg}$ body weight affected the susceptibility of rat plasma to oxidation by AAPH or $\mathrm{Cu}^{2+}$ in $\mathrm{CuSO}_{4}$ solution (Silva et al. 1998). Compared with these studies, it is likely that the amount of EC administered in the present experiment is within the range consumed by eating food, including chocolate and cocoa.

In conclusion, these results indicate that EC in cocoa powder is absorbed from the digestive tract and is present as various conjugated forms in rat plasma, and that cocoa powder enhances the level of antioxidative activity in rat plasma.

\section{Acknowledgements}

We thank I. Komiya, M. Ito, K. Aizawa and N. Okudaira (Meiji Seika Kaisha, Ltd, Pharmaceutical Research Center, Yokohama, Japan) for their technical support in collection of the rat blood and for their helpful suggestions concerning this study.

\section{References}

Afanas'ev IB, Dorozhko AI, Brodskii AV, Kostyuk VA \& Potapovitch AI (1989) Chelating and free radical scavenging mechanisms of inhibitory action of rutin and quercetin in lipid peroxidation. Biochemical Pharmacology 38, 1763-1769.

Bors W, Heller W, Michel C \& Sarah M (1990) Flavonoids as antioxidants: Determination of radical-scavenging efficiencies. Methods in Enzymology 186, 343-355.

Cook NC \& Samman S (1996) Flavonoids: chemistry, metabolism, cardioprotective effects, and dietary sources. Journal of Nutritional Biochemistry 7, 66-76.

Hammerstone JF, Lazarus SA, Mitchell AE, Rucker R \& Schmitz HH (1999) Identification of procyanidins in cocoa (Theobroma cacao) and chocolate using high-performance liquid chromatography/mass spectrometry. Journal of Agricultural and Food Chemistry 47, 490-496.

Harada M, Kan Y, Naoki H, Fukui Y, Kageyama N, Nakai M, Miki W \& Kiso Y (1999) Identification of the major antioxidative metabolites in biological fluids of the rat with ingested (+)-catechin and (-)-epicatechin. Bioscience, Biotechnology, and Biochemistry 63, 973-977.

Hertog MGL, Feskens EJM, Hollman PCH, Katan MB \& Kromhout D (1993) Dietary antioxidant flavonoids and risk of coronary heart disease: the Zutphen Elderly Study. Lancet 342, 1007-1011.
Hertog MGL, Kromhout D, Aravanis C, Blackburn H, Buzina R, Fidanza F, Giampaoli S, Jansen A, Menotti A, Nedeljkovic S, Pekkarinen M, Simic BS, Toshima H, Feskens EJM, Hollman PCH \& Katan MB (1995) Flavonoid intake and long-term risk of coronary heart disease and cancer in the seven countries study. Archives of Internal Medicine 155, 381-386.

Hollman PCH, Tijburg LBM \& Yang CS (1997) Bioavailability of flavonoids from tea. Critical Reviews in Food Science and Nutrition 37, 719-738.

Ishikawa T, Suzukawa M, Ito T, Yoshida H, Ayaori M, Nishiwaki M, Yonemura A, Hara Y \& Nakamura H (1997) Effect of tea flavonoid supplementation on the susceptibility of low-density lipoprotein to oxidative modification. American Journal of Clinical Nutrition 66, 261-266.

Jankun J, Selman SH, Swiercz R \& Skrzypczak-Jankun E (1997) Why drinking green tea could prevent cancer. Nature 387, 561.

Keli SO, Hertog MGL, Feskens EJM \& Kromhout D (1996) Dietary flavonoids, antioxidant vitamins, and incidence of stroke. The Zutphen study. Archives of Internal Medicine 154, 637-642.

Knekt P, Järvinen R, Reunanen A \& Maatela J (1996) Flavonoid intake and coronary mortality in Finland: a cohort study. British Medical Journal 312, 478-481.

Lee M, Wang Z, Li H, Chen L, Sun Y, Gobbo S, Balentine DA \& Yang CS (1995) Analysis of plasma and urinary tea polyphenol in human subjects. Cancer Epidemiology, Biomarkers and Prevention 4, 393-399.

Lotito SB \& Fraga CG (1998) (+)-Catechin prevents human plasma oxidation. Free Radical Biology and Medicine 24, 435441.

Nanjo F, Goto K, Seto R, Suzuki M, Sakai M \& Hara Y (1996) Scavenging effects of tea catechins and their derivatives on 1,1diphenyl-2-picrylhydrazyl radical. Free Radical Biology and Medicine 21, 895-902.

Oguni I, Cheng SJ, Lin PZ \& Hara Y (1992) Protection against cancer risk by Japanese green tea. Preventive Medicine 21, 332.

Okushio K, Suzuki M, Matsumoto N, Nanjo F \& Hara Y (1999) Identification of $(-)$-epicatechin metabolites and their metabolic fate in the rat. Drug Metabolism and Disposition 27, 309316.

Osakabe N, Sanbongi C, Yamagishi M, Takizawa T \& Osawa T (1998a) Effects of polyphenol substances derived from Theobroma cacao on gastric mucosal lesion induced by ethanol. Bioscience, Biotechnology, and Biochemistry 62, 1535-1538.

Osakabe N, Yamagishi M, Sanbongi C, Natsume M, Takizawa T \& Osawa T (1998b) The antioxidative substances in cacao liquor. Journal of Nutritional Science and Vitaminology 44, 313-321.

Piskula MK \& Terao J (1998) Accumulation of (-)-epicatechin metabolites in rat plasma after oral administration and distribution of conjugation enzymes in rat tissues. Journal of Nutrition 128, 1172-1178.

Price MP \& Butler LG (1977) Rapid visual estimation and spectrophotometric determination of tannin content of sorghum grain. Journal of Agricultural and Food Chemistry 25, 12681273.

Ratty AK \& Das NP (1988) Effects of flavonoids on nonenzymatic lipid peroxidation: Structure-activity relationships. Biochemical Medicine and Metabolic Biology 39, 69-79.

Rice-Evans CA, Miller NJ \& Paganga G (1996) Structureantioxidant activity relationships of flavonoids and phenolic acids. Free Radical Biology and Medicine 20, 933-956.

Richelle M, Tavazzi I, Enslen M \& Offord EA (1999) Plasma kinetics in man of epicatechin from black chocolate. European Journal of Clinical Nutrition 53, 22-26.

Sanbongi C, Osakabe N, Natsume M, Takizawa T, Gomi S \& Osawa T (1998) Antioxidative polyphenols isolated from 
Theobroma cacao. Journal of Agricultural and Food Chemistry 46, 454-457.

Silva EL, Piskula M \& Terao J (1998) Enhancement of antioxidative ability of rat plasma by oral administration of (-)-epicatechin. Free Radical Biology and Medicine 24, 12091216.

Silva JMR, Rigaud J, Cheynier V, Cheminat A \& Moutounet M (1991) Procyanidin dimers and trimers from grape seeds. Phytochemistry 30, 1259-1264.

Terao J, Piskula M \& Yao Q (1994) Protective effect of epicatechin, epicatechin gallate, and quercetin on lipid peroxidation in phospholipid bilayers. Archives of Biochemistry and Biophysics 308, 278-284.

Thompson RS, Jacques D, Haslam E \& Tanner RJN (1972) Plant proanthocyanidins. Part I. Introduction; the isolation, structure, and distribution in nature of plant procyanidins. Journal of the Chemical Society Perkin Transactions 1 13, 1387-1399.

Yamanaka N, Oda O \& Nagao S (1997) Green tea catechins such as (-)-epicatechin and (-)-epigallocatechin accelerate
$\mathrm{Cu}^{2+}$-induced low density lipoprotein oxidation in propagation phase. FEBS Letters 401, 230-234.

Yang CS, Chen L, Lee MJ, Balentine D, Kuo MC \& Schantz SP (1998) Blood and urine levels of tea catechins after ingestion of different amounts of green tea by human volunteers. Cancer Epidemiology, Biomarkers and Prevention 7, 351-354.

Yoshino K, Tomita I, Sano M, Oguni I, Hara Y \& Nakano M (1994) Effects of long-term dietary supplement of tea polyphenols on lipid peroxide levels in rats. Age 17, 79-85.

Yu G \& Hsieh C (1991) Risk factors for stomach cancer: a population-based case-control study in Shanghai. Cancer Causes and Control 2, 169-174.

van Acker SA, van den Berg DJ, Tromp MN, Griffioen DH, van Bennekom WP, van der Vijgh WJ \& Bast A (1996) Structural aspects of antioxidant activity of flavonoids. Free Radical Biology and Medicine 20, 331-342.

Zhang A, Zhu QY, Luk YS, Ho KY, Fung KP \& Chen Z (1997) Inhibitory effects of jasmine green tea epicatechin isomers on free radical-induced lysis of red blood cells. Life Sciences $\mathbf{6 1}$, 383-394. 